\title{
ANÁLISE DAS RESERVAS, POTENCIALIDADES E DISPONIBILIDADES DAS ÁGUAS SUBTERRÂNEAS EM MARACANAÚ-CEARÁ
}

Ediu Lopes Lemos ${ }^{1}$

\section{RESUMO}

O desenvolvimento econômico e populacional verificado no município de Maracanaú localizado na Região Metropolitana de Fortaleza (RMF) desencadeou uma demanda progressiva de água para o abastecimento. O objetivo principal deste trabalho foi realizar uma análise quanto as reservas, potencialidades e disponibilidades das águas subterrâneas no município. Inicialmente, se fez uma revisão bibliográfica para compreensão dos aspectos socioeconômicos, geoambientais e hidrogeológicos da área de estudo, em seguida, se obteve dados técnicos dos poços que auxiliaram na caracterização dos sistemas aquíferos e por fim, foram coletados dados pluviométricos que auxiliaram nos cálculos das reservas, potencialidades e disponibilidades das águas subterrâneas. Os resultados dos cálculos de reserva, disponibilidade e potencialidades, demonstram que apesar de volumes significativos de águas nos aquíferos da área de estudo, estes não são suficientes para atender a demanda no abastecimento público, mas, essas águas são importantes reservas hídricas para situações emergenciais.

Palavras-chave: Reservas. Águas subterrâneas. Maracanaú.

\section{ANALYSIS OF THE RESERVES, POTENTIALITIES AND AVAILABILITIES OF GROUNWATERS IN MARACANAÚ-CE}

\begin{abstract}
The economical and population development verified in the municipal district of located Maracanaú in the Metropolitan Area of Fortaleza (RMF) unchained a progressive demand of water for the provisioning. The main objective of this work was to accomplish an analysis as the reservations, potentialities and readiness of the underground waters in the municipal district. Initially, it was made a bibliographical revision for understanding of the socioeconomic aspects, geoambientais and
\end{abstract}

\footnotetext{
${ }^{1}$ Instituto Federal de Ciência e Tecnologia do Espírito Santo, Ifes Campus Nova Venécia, Nova Venécia-ES. Autor para correspondência: ediu.lemos@ifes.edu.br. 
hidrogeológicos of the study area, soon afterwards, it was obtained technical data of the wells that aided in the characterization of the watery systems and finally, they were collected given pluviométricos that aided in the calculations of the reservations, potentialities and readiness of the underground waters. The results of reservation's calculations, readiness and potentialities, they demonstrate that in spite of significant volumes of waters in the watery of the study area, these are not enough to assist the demand in the public provisioning, but, those waters are important reservations hídricas for situations emergenciais.

Keywords: Reserves. Ground water. Maracanaú.

\section{INTRODUÇÃO}

As águas subterrâneas constituem um dos pontos mais relevantes de serem estudados para a implantação de projetos populacionais, industriais ou de irrigação. Na faixa costeira do Ceará é comum observar projetos e/ou comunidades totalmente abastecidas por poços, sejam eles rasos ou profundos, captando água subterrânea para atender demandas diversas.

O desenvolvimento de uma região acarreta um aumento de consumo de água, seja pela elevação do nível de vida, ou pelo surgimento de novas solicitações, a exemplo de atividades de irrigação, industriais, turismo, entre outras, podendo ocorrer o fato de que o referido recurso, que se apresentava em volume satisfatório nas condições iniciais, passe a ser insuficiente para atender às novas demandas, normalmente crescentes (CAVALCANTE \& FRANGIPANI, 2000).

Diante da escassez de água à qual está exposto o Nordeste, em especial o Estado do Ceará, ressaltase a importância dos recursos hídricos subterrâneos disponíveis à exploração e à utilização para os mais diversos fins.

O objetivo geral deste trabalho foi estimar a atual disponibilidade hídrica subterrânea no município de Maracanaú, situado na Região Metropolitana de Fortaleza, tendo em vista a grande utilização da água subterrânea através de poços na região.

A área em estudo apresenta uma grande irregularidade pluviométrica, com picos de seca e períodos com maior incidência de chuvas, ocasionando em alguns anos estado de calamidade em razão das cheias. O conjunto de parâmetros climáticos da área caracterizam o mesmo como clima regional do semiárido (MORAIS et al., 1997). 
Os recursos hídricos subterrâneos da região constituem uma importante fonte de abastecimento das comunidades urbanas e rurais. A área pesquisada é geologicamente constituída por formações Cenozoicas que incluem sedimentos inconsolidados e rochas sedimentares (Formação Barreiras, depósitos colúvio-eluvionares e aluviões) e litotipos Pré-Cambrianos dos Complexos GranitóideMigmatítico e Gnáissico-Migmatítico, que constituem o meio fissural. Nesse contexto, são individualizados quatro sistemas hidrogeológicos com potencialidades hídricas diferenciadas: Cristalino, Barreiras, Misto e Aluviões.

\section{MATERIAIS E MÉTODOS}

Inicialmente, foi feita uma revisão bibliográfica dos trabalhos técnico-científicos realizados, principalmente na Região Metropolitana de Fortaleza (RMF), obtendo dados referentes aos aspectos socioeconômicos, geoambientais, hidrogeológicos e dos recursos hídricos superficiais.

Posteriormente, foram obtidas informações sobre os dados técnicos construtivos, litológicos e hidrogeológicos, para se ter subsídios para o acompanhamento da evolução temporal e da distribuição espacial dos poços de água na área estudada.

Foi feita também a identificação dos sistemas hidrogeológicos tendo como base critérios geológicos obtidos em análises de campo, através da observação da extensão geográfica dos afloramentos e o estabelecimento de correlações com os perfis de poços cadastrados.

Por fim, foram feitos os cálculos das reservas de águas subterrâneas, da potencialidade dos sistemas aquíferos na área, bem como, da disponibilidade hídrica no município e serão descritas nos resultados e discussões de forma detalhada.

\section{RESULTADOS E DISCUSSÃO}

\section{Aspectos hidrogeológicos}

$\mathrm{Na}$ área de estudo foram individualizados quatro sistemas hidrogeológicos: Cristalino, Barreiras, Misto e Aluviões. A identificação desses sistemas teve como base critérios geológicos obtidos em trabalhos de campo, através da análise da extensão geográfica dos afloramentos e a sua correlação com os perfis de poços cadastrados. 
A Figura 1 mostra a distribuição dos poços por sistema aquífero na porção Centro-Norte do município de Maracanaú, sejam eles tubulares profundos ou rasos, manual (cacimbas) ou amazonas. Os poços tubulares sejam profundos ou rasos são poços escavados por máquinas e revestidos por tubulação enquanto os poços do tipo manual ou amazonas são poços escavados de forma artesanal por alguém com uso de enxadas, picaretas e sem nenhum revestimento de tubulação.

Nota-se, a predominância das obras no Sistema Hidrogeológico Cristalino (74,70\%), seguido pelo Barreiras com (15,53\%), Misto (8,80\%) e Aluviões $(0,97 \%)$.

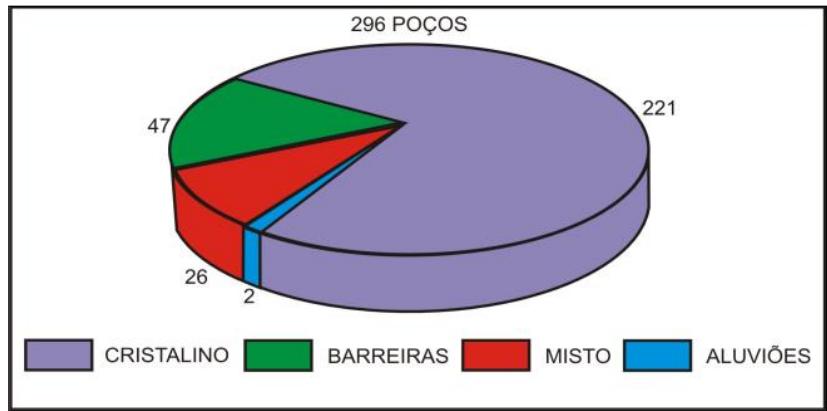

Figura 1 - Distribuição dos poços por sistemas hidrogeológicos na área de estudo.

Apesar do número considerável de poços cadastrados para a área estudada (296 poços), apenas 15 apresentaram fichas técnicas com perfis construtivos/litológicos, representando cerca de $5 \%$ do universo amostral. Essa baixa proporção entre o número de poços cadastrados e a quantidade de perfis construtivos/litológicos restringe uma identificação mais abrangente dos tipos de aquíferos realmente captados.

$\mathrm{Na}$ área de estudo, o Sistema Hidrogeológico Cristalino ocupa uma área aflorante de 58,59 km², sendo representado pelos Complexos Granitóide-Migmatítico e Gnáissico-Migmatítico, os poços tubulares deste contexto apresentam profundidades variáveis de 20 a 138 m, com predomínio de 50 a $60 \mathrm{~m}$ (Figura 2). O nível estático é variável, porém, ocorre um predomínio entre 1 e $10 \mathrm{~m}$ (81,10\%), com mínimo de 0,4 m, máximo de $37 \mathrm{~m}$ e média de 6,07 m. O rebaixamento do nível d'água nos poços do cristalino oscila predominantemente entre 25 e $40 \mathrm{~m}$ (54\%).

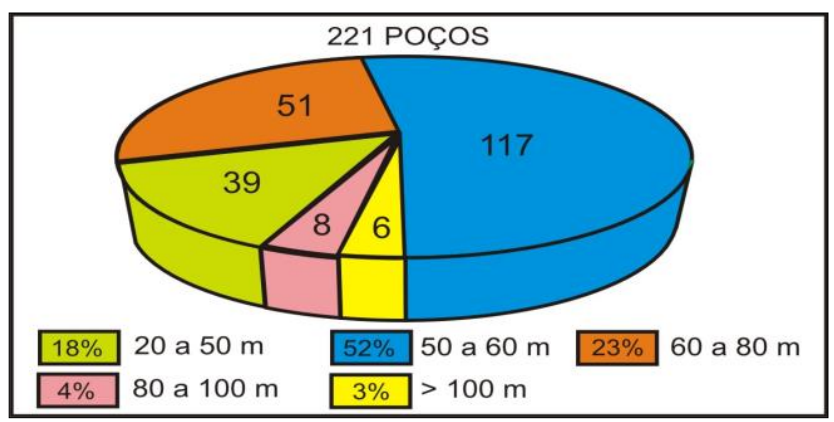

Figura 2 - Profundidade dos poços no Sistema Cristalino na área de estudo. 
As vazões predominantes dos poços são geralmente maiores que $0,03 \mathrm{~m}^{3} / \mathrm{h}$ e menores ou iguais a 1 $\mathrm{m}^{3} / \mathrm{h}(53,6 \%)$, com vazão máxima de $19,3 \mathrm{~m}^{3} / \mathrm{h}$ e a capacidade específica normalmente inferior a $1,0\left[\left(\mathrm{~m}^{3} / \mathrm{h}\right) / \mathrm{m}\right]$. Da soma total, 15 dos poços apresentaram vazões inferiores a $0,03 \mathrm{~m}^{3} / \mathrm{h}$ e foram considerados secos.

No município, observou-se que alguns dos poços dentro desse sistema apresentaram vazões iguais ou superiores a $5 \mathrm{~m}^{3} / \mathrm{h}$, estes poços localizam-se na porção centro-norte da área de estudo, próximos a rede de drenagem do rio Maranguapinho e da lagoa de Maracanaú, sugerindo que estes devem estar recebendo uma recarga das águas superficiais destes corpos d'água através de sistemas de fraturas.

O Sistema Hidrogeológico Barreiras ocupa uma área de $8,66 \mathrm{Km}^{2}$ sendo constituído por sedimentos clásticos Cenozóicos da Formação Barreiras e das coberturas Colúvio-eluvionares.

Dentro do contexto hidrogeológico da Região Metropolitana de Fortaleza, baseando-se em testes de aquífero e de bombeamento, Ribeiro (2001) encontrou para o aquífero Barreiras valores de 4,65 x $10^{-4} \mathrm{~m} / \mathrm{s}$ e de $4,78 \times 10^{-3} \mathrm{~m}^{2} / \mathrm{s}$ para a condutividade hidráulica $(\mathrm{K})$ e transmissividade $(\mathrm{T})$, respectivamente.

Os poços tubulares deste sistema possuem profundidades entre 10 a 15 m (66\%). O nível estático é variável, predominando $6 \mathrm{~m}$ (72,5\%), com mínimo de $1 \mathrm{~m}$, máximo de $10 \mathrm{~m}$ e média de 4,43 m, admite-se uma espessura saturada de $7 \mathrm{~m}$, apresentam vazões normalmente inferiores a $2 \mathrm{~m}^{3} / \mathrm{h}$, tendo como fatores de recarga a precipitação pluviométrica diretamente sobre sua área aflorante, os cursos fluviais, os açudes e as lagoas intermitentes da região.

O Sistema Hidrogeológico Misto localiza-se em pequenas áreas do Barreiras, sendo que 26 poços foram considerados como captando água subterrânea desse sistema. Um pouco mais da metade desses poços (66\%), depois de atravessarem o Barreiras, penetram o embasamento cristalino por mais de $40 \mathrm{~m}$, em média, enquanto os $34 \%$ restantes penetram no cristalino $50 \mathrm{~m}$ em média, caracterizando um sistema misto de captação, uma vez que as entradas d'água ocorrem tanto nos filtros dispostos na sequência formada por sedimentos arenosos do Barreiras como em fraturas das rochas do Complexo Gnáissico-Migmatítico situadas abaixo, como mostra o exemplo da Figura 3. Representam 8,5\% dos poços cadastrados, sendo a maioria desses poços do tipo tubular profundo $(90 \%)$. 


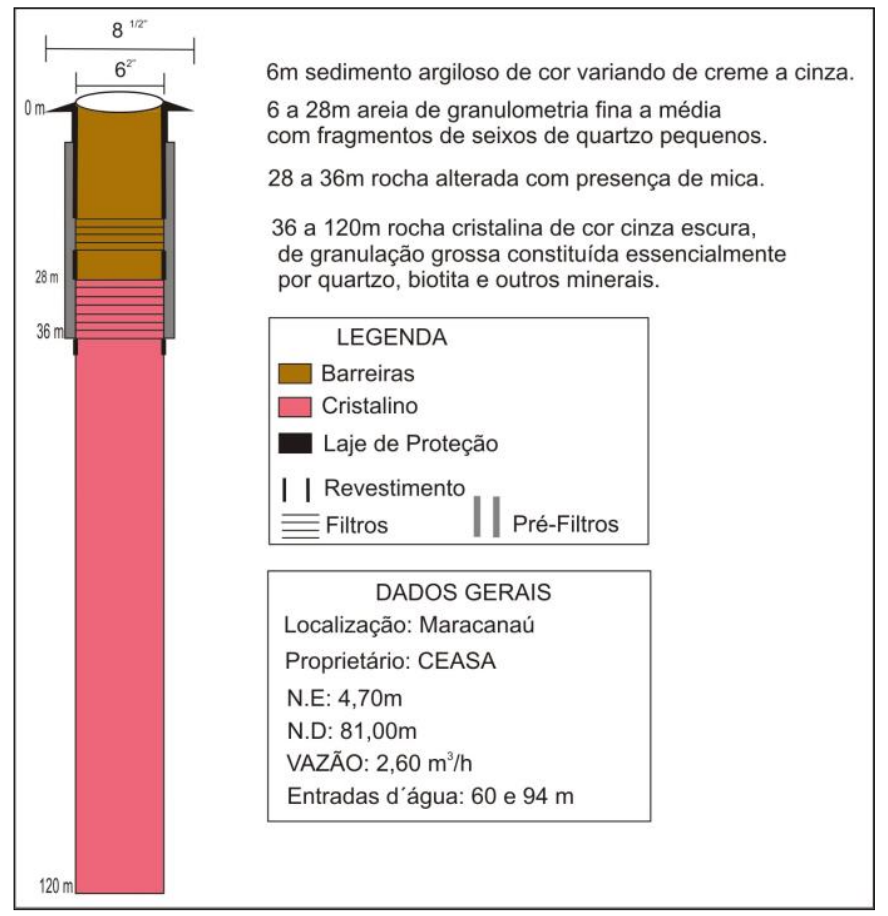

Figura 3 - Poço captando o Sistema Misto.

De acordo com dados de 26 poços cadastrados desse sistema, observa-se que as profundidades situam-se entre 25 e $123 \mathrm{~m}$, com média de $58 \mathrm{~m}$, as vazões predominantes são geralmente abaixo de $2 \mathrm{~m}^{3} / \mathrm{h}(28 \%)$, chegando a valores mínimos e máximos de $0,30 \mathrm{~m}^{3} / \mathrm{h}$ e $4,5 \mathrm{~m}^{3} / \mathrm{h}$, respectivamente, e média de $1,87 \mathrm{~m}^{3} / \mathrm{h}$. A capacidade específica, semelhante ao que ocorre com os poços construídos do meio cristalino, é normalmente inferior a $1,0\left[\left(\mathrm{~m}^{3} / \mathrm{h}\right) / \mathrm{m}\right]$.

O Sistema Hidrogeológico Aluvionar corresponde às deposições efetuadas no Quaternário, formadas por material arenoso de granulometria grossa a fina, siltes e argilas que ocorrem na área margeando os baixos cursos dos principais rios (Timbó e Maranguapinho). Formam faixas alongadas, respectivamente, de direção NW-NE e NW-SW.

Em função da pouca ocupação urbana nesses terrenos, foram cadastrados apenas 02 poços tipo amazonas nesse domínio. Esses poços foram construídos manualmente e possuem grande diâmetro (em média 6,5 m), captando água com profundidades de $16 \mathrm{~m}$ e $20 \mathrm{~m}$, e nível estático de 2,65 m e 4,0 m, respectivamente.

Com relação a parâmetros hidrodinâmicos desse sistema, BARROS et al. (1981) encontraram valores para transmissividade igual a $3,0 \times 10^{-3} \mathrm{~m}^{3} / \mathrm{s}$, permeabilidade de $6,0 \times 10^{-4} \mathrm{~m} / \mathrm{s}$ e porosidade efetiva de 5,0 $\times 10^{-2}$. Esses valores apresentam similaridade com os valores encontrados para a Formação Barreiras, demonstrando que os limos sílticos-argilosos existentes nos litotipos da 
unidade, também limitam na sua capacidade de armazenamento e liberação de água.

\section{Reservas, Potencialidades e Disponibilidades das águas subterrâneas}

Os conceitos adotados para a definição do cálculo de reservas foram os estabelecidos por Costa (1997, 1998) e ratificados por Veríssimo (1999). Esses conceitos que elucidam, além das reservas (reguladora, permanente e total), a potencialidade e a disponibilidade (potencial e efetiva) hídrica subterrânea serão apresentados juntamente com os respectivos cálculos.

$\mathrm{Na}$ presente área ocorrem dois contextos litológicos distintos: o sedimentar representado pelos depósitos Aluvionares e Barreiras, e o Cristalino representado pelas rochas dos Complexos GranitoMigmatítico e Gnáissico-Migmatítico.

\section{Reservas reguladoras}

As reservas reguladoras representam à quantidade de água acumulada no meio aquífero, em função da porosidade eficaz ou do coeficiente de armazenamento que sofre variação anual em decorrência dos aportes sazonais de água (superficial e/ou pluviométrica), do escoamento subterrâneo e dos exutórios, tendo uma flutuação sazonal do aquífero livre (REBOUÇAS, 1997).

O cálculo das reservas reguladoras, ou transitórias, pode ser efetuado de várias maneiras. Uma das maneiras é utilizando-se o método volumétrico, que tem por base a flutuação $(\Delta \mathrm{h})$ dos níveis d'água nos aquíferos livres, sendo mostrada na expressão: $\operatorname{Rr}=\mathrm{A} x \Delta \mathrm{h} x \eta \mathrm{\eta}$, Onde: $\mathrm{A}=$ área de ocorrência do aquífero $\left(\mathrm{L}^{2}\right), \Delta \mathrm{h}=$ variação do nível d'água $(\mathrm{L})$ e $\eta \mathrm{n}=$ porosidade efetiva (adimensional).

Considerando-se uma precipitação pluviométrica média de $1153 \mathrm{~mm} / \mathrm{ano}$ na área, o volume precipitado sobre a área de ocorrência do Barreiras $\left(8,66 \mathrm{~km}^{2}\right)$ é de 9,98 milhões de $\mathrm{m}^{3} /$ ano. Utilizando $\mathrm{Rr}=\mathrm{A} . \Delta \mathrm{h}$. $\eta$ e onde $\mathrm{A}=8,66 \mathrm{~km}^{2}, \Delta \mathrm{h}=0,5 \mathrm{~m}$ e $\eta \mathrm{e}=5 \%$, obtém-se para as reservas reguladoras, ou renováveis, do Sistema Barreiras um volume de $216.500 \mathrm{~m}^{3} / \mathrm{ano}$.

O Sistema Aluvionar é litologicamente constituído por argilas, areias argilosas, areias puras e cascalhos com ou sem matéria orgânica, ocupa uma área de $0,79 \mathrm{~km}^{2}$, sobre a qual precipita um volume de 9,1 milhões de $\mathrm{m}^{3} /$ ano.

Para a variação do nível d'água $(\Delta \mathrm{h})$, Barros et al. (1991) trabalharam com uma variação anual de 
0,072 m nesse sistema. Quanto à porosidade efetiva ( $\eta$ e), o valor adotado é de 7\%, 40\% maior que o utilizado para o Sistema Barreiras, corroborando à similaridade entre os parâmetros hidrodinâmicos dos dois sistemas, conforme exposto anteriormente.

Assim, utilizando $\mathrm{Rr}=\mathrm{A} . \Delta \mathrm{h} . \quad \eta \mathrm{e}$ onde $\mathrm{A}=0,79 \mathrm{~km}^{2}, \Delta \mathrm{h}=0,072 \mathrm{~m} / \mathrm{ano}$ e $\eta \mathrm{e}=7 \%$, obtémse para as reservas reguladoras, ou renováveis, do Sistema Aluvionar um volume de $3.982 \mathrm{~m}^{3} / \mathrm{ano}$.

\section{Reservas permanentes}

As reservas permanentes representam o volume de água subterrânea que participa do ciclo hidrológico numa escala de tempo plurianual, centenária ou milenar. Correspondem aos volumes estocados abaixo do limite inferior de flutuação sazonal do nível de saturação dos aquíferos livres ou dos níveis potenciométricos dos aquíferos confinados (REBOUÇAS, 1997).

As reservas permanentes podem ser calculadas pelo método volumétrico, utilizando-se a seguinte fórmula: $R p=\mathrm{A}$ x ho $\mathrm{x} \eta \mathrm{\eta}$, onde $\mathrm{A}=$ área de ocorrência do sistema aquífero $\left(\mathrm{L}^{2}\right)$, ho = espessura média saturada (L), já que na área de trabalho ocorrem aquíferos do tipo livre, e ๆe = porosidade efetiva (adimensional).

Para o Sistema Barreiras que possui uma área de $\left(8,66 \mathrm{~km}^{2}\right)$, considerando-se uma espessura saturada (ho) de $7 \mathrm{~m}$, e uma porosidade efetiva ( $\eta$ e) de $5 \%$, calcula-se uma reserva hídrica permanente $(\mathrm{Rp})$ igual a $3.031 .000 \mathrm{de}^{3}$.

Já para o Sistema Aluvionar, que ocupa uma área de $\left(0,79 \mathrm{~km}^{2}\right)$ e considerando-se uma espessura média saturada (ho) de $5 \mathrm{~m}$ e porosidade efetiva ( $\eta$ e) de $7 \%$, existe uma reserva hídrica permanente (Rp) de $276.500 \mathrm{~m}^{3}$.

\section{Reservas totais}

O conjunto das reservas reguladoras e permanentes representa as reservas totais, ou naturais, consistindo, dessa forma, na totalidade das águas que ocorrem num aquífero ou em um sistema hidrogeológico $(R t=\mathrm{Rr}+\mathrm{Rp})$. Dessa forma as reservas totais $(\mathrm{Rt})$ para o Sistema Hidrogeológico Barreiras são de 3.247.500 de $\mathrm{m}^{3}$. Já para o Sistema Hidrogeológico Aluvionar as reservas totais (Rt) são de $280.482 \mathrm{~m}^{3}$.

\section{Potencialidades}


Na definição de Veríssimo (1999), potencialidade constitui o volume hídrico que pode ser utilizado anualmente incluindo, eventualmente, uma parcela das reservas permanentes passível de ser explorada com descarga constante durante um determinado tempo.

Assim, para o cálculo da potencialidade foi utilizada a expressão: $\mathrm{P}=(\mathrm{Rp} \times \mathrm{i})+\mathrm{Rr}$, onde: $\mathrm{Rp}=$ reserva permanente $\left(\mathrm{m}^{3}\right) \mathrm{Rr}=$ reserva reguladora $\left(\mathrm{m}^{3} / \mathrm{ano}\right), \mathrm{i}=$ percentual da reserva permanente a ser utilizado (\%). Da mesma forma que as reservas, o cálculo para potencialidades foi efetuado somente para os Sistemas Barreiras e Aluvionar.

Assim, para o Sistema Hidrogeológico Barreiras, utilizando $P=(\operatorname{Rp} x$ i $)+R r$, onde $R p=3.031 .000$ de $\mathrm{m}^{3} /$ ano, $\mathrm{Rr}=216.500 \mathrm{~m}^{3}, \mathrm{i}=0,6 \%$, obtém-se $234.686 \mathrm{~m}^{3}$ para a potencialidade hídrica subterrânea desse sistema.

Já para o Sistema Hidrogeológico Aluvionar, onde $\mathrm{Rp}=276.500 \mathrm{~m}^{3} / \mathrm{ano}, \mathrm{Rr}=3.982 \mathrm{~m}^{3}, \mathrm{i}=0,6 \%$, temos sua potencialidade de $5.641 \mathrm{~m}^{3}$.

Considerando-se o volume potencial de $240.327 \mathrm{~m}^{3}$, os Sistemas Hidrogeológicos Barreiras e Aluvionar apresentam um potencial hídrico em torno de $658.000 \mathrm{~L} /$ dia.

\section{Disponibilidade}

Constitui os recursos hídricos explotáveis que estão disponíveis e que não comprometem as reservas do aquífero nem o meio ambiente. De acordo com Cavalcante (1998), podem ser classificadas como disponibilidade potencial e efetiva.

\section{Disponibilidade potencial}

A disponibilidade potencial do sistema aquífero considera explotável o volume total da reserva renovável e, consequentemente, não acarreta depleção à reserva permanente.

Para os Sistemas Hidrogeológicos Barreiras e Aluvionar, a disponibilidade potencial é representada pela reserva renovável mais uma parcela da permanente, calculada em função das variáveis de decisão. Na prática, corresponde a 1/3 das reservas totais, ou seja, $1.082 .500 \mathrm{de}^{3}$, para o Sistema Barreiras, e $93.494 \mathrm{~m}^{3}$ para o Sistema Aluvionar.

\section{Disponibilidade efetiva}

A disponibilidade efetiva representa o volume normalmente captado pelos poços instalados, sendo 
recomendável, segundo Cavalcante (1998), se considerar o tempo adotado para a vida útil do poço (20 anos), a vazão média do sistema aquífero captado e o tempo médio de bombeamento que varia de acordo com a necessidade do usuário e/ou capacidade do aquífero.

Para o período de 1938 a 2002 foram cadastrados 296 poços. No entanto, foi tomada como referência apenas as vazões dos poços construídos nos últimos 20 anos (média de vida útil de um poço). Desse universo de 296 poços, apenas 137 encontram-se em uso e apresentam dados de vazão, sendo a média igual a $1,87 \mathrm{~m}^{3} / \mathrm{h}$.

A disponibilidade efetiva $\left(\mathrm{D}_{\mathrm{e}}\right)$ dos poços cadastrados teve como base à vazão média atual dos poços captados, multiplicada pelo total de horas em que o poço é utilizado, de acordo com a seguinte equação: $D_{\mathrm{e}}=\mathrm{n} \times \mathrm{Qm} \times \mathrm{t}_{\mathrm{h}}$, onde $\mathrm{n}=$ número de poços existentes, $\mathrm{Qm}=$ vazão média e $\mathrm{t}_{\mathrm{h}}=$ número de horas de bombeamento durante o ano.

Tomando-se por base a quantidade de 41 poços em funcionamento nos Sistemas Barreiras e Aluvionar na área de estudo e um regime de bombeamento de seis (6) horas diárias, temos que a disponibilidade efetiva $\left(\mathrm{D}_{\mathrm{e}}\right)$ calculada é de $167.907 \mathrm{~m}^{3} / \mathrm{ano}$, correspondendo a $76,15 \%$ dos 220.482

$\mathrm{m}^{3}$ /ano da soma das reservas renováveis dos Sistemas Barreiras e Aluvionares e representa 5,07\% das reservas permanentes desses sistemas.

Transformada em valor diário, a disponibilidade efetiva é de 460,019 $\mathrm{m}^{3} / \mathrm{dia}$ (ou $460.019 \mathrm{~L} / \mathrm{dia}$ ), o que corresponde ao abastecimento de uma população de 2.300 habitantes.

\section{CONCLUSÕES}

A falta de um banco de dados com informações disponíveis sobre perfis litológicos, perfis construtivos, análises físico-químicas, parâmetros hidrodinâmicos e coordenadas de um mesmo poço, não permite diferenciar com exatidão a água subterrânea proveniente dos sedimentos Terciários da água proveniente do embasamento.

As reservas, potencialidades e disponibilidade aqui calculadas, demonstram que apesar de apresentarem volumes significativos de águas nos aquíferos do município de Maracanaú, estes não seriam suficientes para atender a demanda da população no abastecimento público, porém, essas águas são importantes reservas hídricas para situações emergenciais. 


\section{REFERÊNCIAS}

BARROS, M.J.G; RIBEIRO, A.G; LIMA, E.A.; FONSECA, R.A. Potencial dos Recursos Hídricos. In: BRASIL. Ministério das Minas e Energia - Projeto RADAMBRASIL - 1981 - Levantamento de Recursos Naturais. Folha Jaguaribe. SB 24/25. Jaguaribe/Natal; Geologia, Geomorfologia, Pedologia, Vegetação e Uso Potencial da Terra. Rio de Janeiro. 1991.

CAVALCANTE, I.N.; FRANGIPANNI, A. Gestão das Águas - Uma política de Sobrevivência. In: CONGRESSO MUNDIAL INTEGRADO DAS ÁGUAS SUBTERRÂANEAS, 1, 2000, Anais... Fortaleza: ABAS/ALSHUD, 1998.

CAVALCANTE, I.N. Fundamentos hidrogeológicos para gestão integrada de recursos hídricos na Região Metropolitana de Fortaleza, Estado de Ceará. 1998, 164f. Tese de Doutorado em Recursos Minerais e Hidrogeologia, Instituto de Geociências, Universidade de São Paulo, São Paulo, São Paulo, 1998.

COSTA, W. D. Estudo da Disponibilidade Hídrica da Lagoa do Bonfim no Município de Nísia Floresta - RN. SERHID/COSTA. Consultoria e Serviços Técnicos e Ambientais Ltda. Natal/RN. 83p. 1997.

COSTA, W.D. Avaliação de Reservas e Potencialidade de Aquíferos. In: CONGRESSO BRASILEIRO DE ÁGUAS SUBTERRÂNEAS, 10, 1998, São Paulo. Anais... São Paulo: ABAS, 1998.

MORAIS, J.O. (Coord.) Diagnóstico geoambiental da bacia do Baixo Jaguaribe. Etapa I. Zoneamento ecológico e econômico do Baixo Jaguaribe: Relatório Técnico CNPq. Fortaleza: Universidade Estadual do Ceará, 1997.

REBOUCAS, A.C. Água na região Nordeste: desperdício e escassez. Estudos Avançados, São Paulo, v.11, n. 29, p.127-154, 1997.

RIBEIRO, J.A.F. Características Hidrogeológicas e Hidroquímicas da Faixa Costeira Leste da Região Metropolitana de Fortaleza, Ceará. 2001. 112f. Dissertação de Mestrado em Geologia, Centro de Ciências, Universidade Federal do Ceará, Fortaleza, 2001.

VERÍSSIMO, L.S. Importância das Águas Subterrâneas para o Desenvolvimento Socioeconômico do Eixo CRAJUBAR, Cariri Ocidental, Estado do Ceará. 1999. 128f. Dissertação de Mestrado em Hidrogeologia, Centro de Ciências, Universidade Federal do Ceará, Fortaleza, 1999. 